\title{
Acessibilidade e sustentabilidade: a experiência da hotelaria de Brasília
}

\section{Accessibility and sustainability: the experiences of hospitality in Brasilia}

\section{Accesibilidad y sostenibilidad: la experiencia de la hospitalidad de Brasilia}

\section{Donária Coelho Duarte ${ }^{1}$ Gilson Zehetmeyer Borda ${ }^{2}$}

Resumo: $\mathrm{O}$ artigo reflete sobre a relação entre Acessibilidade e Sustentabilidade focalizando as Pessoas com Deficiência ou Mobilidade Reduzida (PDMR) - aí incluídas pessoas com algum tipo de deficiência sensorial ou motora, pessoas na denominada "terceira idade", pessoas com obesidade, grávidas, pais com filhos até 5 anos de idade e outros. Analisa a perspectiva do turismo no Brasil nos próximos anos, partindo do cenário atual de preparação para a realização de mega eventos esportivos, dentre os quais a Copa do Mundo FIFA 2014 contrapondo-se à crise econômica global. Destaca-se as PDMR como um segmento turístico com grande potencial de crescimento, desde que seja fornecida infraestrutura pública e nos equipamentos turísticos para o seu melhor atendimento. $O$ artigo focaliza as PDMR como turistas, discutindo como está a adaptação do setor hoteleiro de Brasília para o pleno atendimento das necessidades dessas pessoas e trata ainda da inserção econômica e inclusão social das PDMR como colaboradores dessas organizações. Dentre os dados coletados na pesquisa de campo, salienta-se que: dos 29 hotéis pesquisados, 23 afirmam que possuem instalações adaptadas. Destes, 20 adaptaram suas instalações por exigência da lei. A maioria (26 hotéis) aparenta estar preocupada ou já preparada para um potencial aumento de demanda. 21 entrevistados consideram que há uma procura frequente da parte de hóspedes pertencentes à terceira idade. Nas conclusões, são elencadas algumas sugestões visando a melhoria da acessibilidade e sustentabilidade da rede hoteleira de Brasília. Estimula-se ainda o aprofundamento das pesquisas sobre o tema.

Palavras-chave: Acessibilidade; Terceira idade; Deficientes; Hotéis; Brasília.

Abstract: The article reflects on the relationship between accessibility and Sustainability focusing on People with Disabilities or Reduced Mobility (PWDRM) - including people with some sensory or motor disability

\footnotetext{
${ }^{1}$ Professora e pesquisadora do Centro de Excelência em Turismo - Universidade de Brasília (UnB), pesquisadora em Turismo e Sustentabilidade Social do LETS - Laboratório de Estudos em Turismo e Sustentabilidade (Centro de Desenvolvimento Sustentável - UnB). É pesquisadora responsável pela linha de pesquisa Turismo para Todos: Acessibilidade e Inserção Econômica. Doutora em Engenharia de Produção pela Universidade Federal de Santa Catarina (Brasil). Email: donaria@unb.br; donaria@hotmail.com

2 Professor e pesquisador do Centro de Excelência em Turismo - Universidade de Brasília (UnB), Pesquisador em Turismo e Sustentabilidade Social do LETS - Laboratório de Estudos em Turismo e Sustentabilidade (Centro de Desenvolvimento Sustentável - UnB). Coordenador da Linha de Pesquisa Turismo Responsável: Turismo Acessível e Turismo Sênior - Inclusão Social e Inserção Econômica. Doutor em Sociologia Econômica pela Universidade de Brasília (Brasil). Email: gborda@unb.br; gborda@cnpq.br
} 
and people in the so called "third age". It analyses the prospect of tourism in Brazil in the coming years, based on the current preparation scenario for holding mega sporting events - among them FIFA 2014 World Cup - in opposition to the global economic crisis. It highlights the PWDRM as a segment with high potential growth, since it is provided public infrastructure and tourism facilities for their best care. The article focuses on the PWDRM as tourists, discussing how it is ocurring Brasilia Hospitality Industry adapting process to fully adressing the needs of these people. It study also the economic integration and social inclusion of PWDRM as employees of these organizations. Among the data collected in the field research, it emphasizes that from the 29 hotels surveyed, 23 declare having PWDRM adapted facilities, of which 20 have adapted their facilities only due to law requirements. The majority (26 hotels) appear to be concerned or already prepared for a potential increase in demand and 21 respondents consider that there is a growing demand from senior guests. Finally, suggestions are made looking for a better accessibility and sustainability in the Brasilia Hospitality Sector and is encouraged a deeper research. Further research is recommended in the subject.

Keywords: Accessibility; Seniors; Hotel; Brasilia.

Resumen: El artículo reflexiona sobre la relación entre la accesibilidad y la sostenibilidad. Se centra en las personas con minusvalía (PCM) - incluye las personas con algún tipo de discapacidad sensorial o motora, las personas mayores, las personas obesas, mujeres embarazadas, familias con niños hasta 5 años y otros. Analiza las perspectivas del turismo en Brasil en los años siguientes, desde el escenario actual de preparación para la celebración de mega eventos deportivos - entre ellos el Mundial de Fútbol de la FIFA 2014 - en contra posición a la crisis económica global. Destacase el sector turístico Minusválido con gran potencial de crecimiento, ya que se entrega la infraestructura pública y servicios turísticos para su mejor atención. El artículo concentra en las PCM como turistas, está discutiendo cómo adaptar la industria hotelera de Brasilia para atender plenamente las necesidades de estas personas y hacer frente a la integración económica y la inclusión social de los Minusválidos como empleados de estas organizaciones. Entre los datos recogidos en la investigación de campo, se observa que: de 29 hoteles encuestados, 23 dicen que adaptaram sus instalaciones a las PCM. De éstos, 20 han adaptado sus instalaciones como lo requiere la ley. Casi todos ( 26 hoteles) parecen preocuparse o ya estar preparados para un posible crecimiento de la demanda. 21 encuestados consideran que existe una demanda frecuente por parte de los clientes que pertenecen a los mayores. En las conclusiones se enumeran algunas sugerencias para la mejoría de la accesibilidad y la sostenibilidad de la cadena hotelera de Brasilia. También se alienta la profundización de la investigación del tema.

Palabras clave: Accesibilidad; La Tercera Edad; Hoteles; Brasilia.

\section{INTRODUÇÃO}

Atualmente assuntos relacionados a desigualdade e responsabilidade social tem permeado a esfera pública e privada da sociedade brasileira. Esse fato parece acontecer devido a um novo cenário que vem se delineando: uma maior atenção à sustentabilidade (Borda, 2009).

Assim, entendendo-se a responsabilidade social como um meio para a equidade de direitos em sociedade, percebe-se que a mesma engloba vários aspectos, dentre esses, a inserção das Pessoas com Deficiência ou Mobilidade Reduzida (PDMR) no convívio social.

Com relação a pessoas com incapacidade ou deficiência, o Censo Demográfico Brasileiro de 2010 indicou que aproximadamente 45,6 milhões de pessoas, ou 23,9\% da população total, apresentaram algum tipo de incapacidade ou deficiência. Um crescimento respeitável em relação 
ao último Censo Demográfico, realizado em 2000, quando 24,6 milhões de pessoas, ou $14,5 \%$ da população total, assinalaram algum tipo de deficiência (IBGE, 2010).

A Secretária de Estado dos Direitos da Pessoa com Deficiência de São Paulo, Dra. Linamara Rizzo Battistella, avalia esse aumento positivamente destacando que as questões de inclusão e acessibilidade tem ganho maior interesse e reflexão (IBGE, 2010).

Referentemente à terceira idade, o aumento da idade média da população mundial e do número de idosos no mundo tem se acelerado (Moscardo, 2006). Na União Européia, a população com idades superiores a 65 anos atingirá mais que 30\% da população Europeia em 2060 (contra 17,4\% em 2010), enquanto a população com idade igual ou acima dos 80 anos tende a quase triplicar até $2060^{3}$ (Eurostat, 2011). No caso do Brasil, até 2025 o país terá uma população de 32 milhões de pessoas com mais de 60 anos, colocando o país na 6a posição em número de idosos (IBGE, 2010).

Quando se trata da inserção de pessoas portadoras de deficiência no mercado de trabalho, a proporção de pessoas ocupadas de 10 anos ou mais de idade é de $60,3 \%$ para os homens portadores de deficiência e de $71,0 \%$ para os homens que declararam não possuir nenhuma deficiência, ou seja, uma diferença maior que 10\%. Diferença ainda maior é observada entre as mulheres: as mulheres que trabalham fora representam $51,4 \%$ da população contra $37,8 \%$ das mulheres com deficiência (IBGE, 2010).

Este novo cenário tende a impactar várias áreas/setores. No turismo, uma vertente que surgiu denomina-se "turismo inclusivo" que, conforme Bóia (2000), é aquele que acompanha o movimento da sociedade inclusiva e que representa o conjunto de práticas e atitudes que levam em consideração as necessidades de todos os turistas.

A linha de Turismo para a Sustentabilidade que mais tem crescido no mundo é o Turismo Responsável (Goodwin, 2011). Uma das primeiras declarações sobre Turismo Responsável - Cape

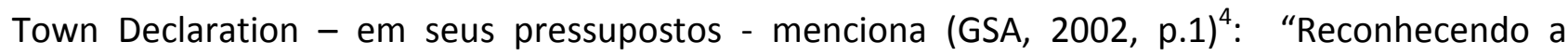
importância do Código Global de Ética da Organização Mundial do Turismo, que objetiva promover um turismo responsável, sustentável e universalmente acessível [...]" e continua chamando os atores da cadeia produtiva do turismo a (GSA, 2002, p.4 ): "esforçar-se para fazer o turismo uma experiência socialmente inclusiva e garantir que haja acesso para todos, em especial as comunidades e indivíduos vulneráveis e desfavorecidos".

Neste aspecto, vale lembrar que o turismo inclusivo não abrange apenas os deficientes físicos mas também as pessoas denominadas com mobilidade reduzida, incluindo também aquelas que possuem algum tipo de limitação que, porventura, possa ser momentânea. Portanto, Devile

${ }^{3}$ Destaca-se ainda que "o aumento substancial da população acima dos 80 anos levará, naturalmente, a novas procuras de mercado turístico, onde temas como saúde, bem-estar e acessibilidade se devem apresentar como fundamentais" (UA/INATEL, 2012, p.3).

4 Recognising the importance of the World Tourism Organization's Global Code of Ethics, which aims to promote responsible, sustainable and universally accessible tourism[...] (Tradução Livre).

5 Endeavour to make tourism an inclusive social experience and to ensure that there is access for all, in particular vulnerable and disadvantaged communities and individuals." (Tradução Livre) 
(2009) acrescenta a esse grupo, pessoas que sofrem temporariamente os efeitos de um acidente, pais que transportam carrinhos de bebês, viajantes com bagagens pesadas, famílias acompanhadas de crianças ou de idosos. Papamichail (2012) ainda complementa esse segmento com pessoas alérgicas, aquelas com dificuldade de aprendizado, pessoas muito baixas ou obesas, pessoas com problemas de saúde, como, por exemplo, problemas circulatórios, dentre outros.

Desta forma, para Garcia-Caro, Waal \& Buhalis (2012), novos padrões de desenvolvimento do turismo estão se direcionamento para novas questões críticas, tais como qualidade, sustentabilidade, imagem, inovação e acessibilidade.

Devile (2002) considera que o grupo de turistas classificados como deficientes ou com mobilidade reduzida tem, mais do que qualquer outro, necessidade de uma informação específica detalhada e fidedigna para a decisão das suas opções de férias de modo a evitar situações constrangedoras e experiências desagradáveis durante uma viagem. Complementando, Silva \& Bóia (2003) entendem que este segmento, além de mais bem informado de seus direitos e mais exigente, busca qualidade nos serviços, quando dedica seu tempo livre ao turismo. Corroborando, García-Caro, Waal \& Buhalis (2012) consideram que acessibilidade e turismo são dois conceitos relacionados e que o turismo acessível é uma importante oportunidade de negócios.

Evidenciando especificamente o turismo sênior, Cavaco (2009) menciona que este valoriza o fator de desenvolvimento integral do homem e que reconhece o turismo como instrumento de integração social, de acesso à cultura, um turismo para todos, visando a sua democratização. Conforme o destaque do autor, o turismo sênior faz parte do turismo social, sendo, portanto, um turismo inclusivo. Assim, a busca da inclusão das pessoas com deficiência ou mobilidade reduzida no turismo faz parte de um processo de mudança na forma de planejar o turismo.

Acrescenta-se aos fatores expostos anteriormente, o fato do Brasil ser sede de mega eventos esportivos como a Copa do Mundo em 2014 e as Olimpíadas e Paraolimpíadas em 2016, o que pode ocasionar um acréscimo de demanda desse público aos serviços turísticos.

Entretanto, independente da realização de mega eventos, entende-se que o Brasil como país receptor, deve cumprir com certas obrigações. Dentre essas obrigações está a acessibilidade, a infra estrutura, comunicação, transporte, dentre os mais candentes. Desta forma, as diferentes cidades-sede deverão ser espaços marcados para a acessibilidade dos segmentos turísticos em discussão.

Com base nos desafios previstos para a economia global de forma geral e o turismo em particular se apresentou a questão: Tendo em vista o enfoque atual do turismo responsável e, sobretudo, da acessibilidade, como o setor hoteleiro da capital federal está preparado para receber pessoas com deficiência ou mobilidade reduzida?

$\mathrm{O}$ atendimento das necessidades desse público, desde seu destino de origem até a chegada nos vários destinos turísticos brasileiros, possibilitará um crescimento contínuo e vigoroso - nos próximos anos - desse segmento que possui necessidades de infra-estrutura, de cuidado e atenção pessoais. Esse artigo tem o objetivo de verificar, com base em pesquisa de 
campo realizada pelos autores, a situação da hotelaria de Brasília em relação à adaptabilidade e acessibilidade ao público de Pessoas com Deficiência ou Mobilidade Reduzida visando a sua inclusão social e inserção econômica, além de seu potencial de crescimento mercadológico.

\section{AS PESSOAS COM DEFICIÊNCIA OU MOBILIDADE REDUZIDA (PDMR) NO CONTEXTO TURÍSTICO}

Este artigo analisa a inclusão social focalizando a questão de importância crescente no turismo e que tem ganhado maior visibilidade nos últimos anos: o turismo acessível.

Assim, como este trabalho propõe estudar formas de inclusão social, por meio do turismo acessível, busca-se com esse enfoque reduzir a exclusão social.

Nascimento (1994) pontua a reflexão sobre a exclusão social conectando-a ao não reconhecimento de direitos existentes, reais - do outro -; assim, o ator social A marginaliza o ator $B$, rejeitando-o ou não tolerando o exercício de seus direitos legítimos.

Com relação ao exercício pleno dos seus direitos, Pinto (2012) considera que nas últimas décadas pessoas com deficiência e pesquisadores em todo o mundo têm contribuído para a mudança radical das percepções sociais sobre a deficiência. A autora considera que essa mudança implicou também uma reconsideração dos dilemas da igualdade e da diferença no contexto da deficiência.

Se analisarmos especificamente o turismo, Fialho (2009) defende que o mesmo é um bem social e que deve estar ao alcance de todos os cidadãos, entre os quais as pessoas portadoras de deficiência.

Assim, entende-se que a acessibilidade no turismo visa, primordialmente, o reconhecimento do outro (o deficiente) em seus direitos e responsabilidades. Busca, portanto, colocá-lo não como alguém "digno de pena", mas como alguém capaz de exercer todas as atividades turísticas de forma equânime - como um igual.

De acordo com o MTur (2006), a acessibilidade é a condição básica para que uma pessoa com deficiência ou mobilidade reduzida possa utilizar com segurança e autonomia, seja ela assistida ou não, de espaços, mobiliários e equipamentos urbanos, edificações, transportes e meios de comunicação.

Duarte (2005) considera que a atividade turística, inclusive devido a sua característica de pluralidade, de diversidade de povos, raças, credos, etc. deve ser receptiva a qualquer indivíduo, inclusive para aqueles que possuem alguma limitação física. Desta forma, os princípios do turismo inclusivo devem visar um turismo para todos aqueles que desejam usufruir tais serviços.

Em relação a adaptação no ambiente físico, Serpa (2009) discute o turismo voltado para as PDM como aquele que apresenta a facilidade de acesso a um determinado destino ou atrativo turístico com a existência de vias e de meios de transporte até o local, adaptar um ambiente para que pessoas com deficiência possam usufruí-lo nas mesmas condições que uma pessoa sem deficiência, entre outras adaptabilidades que facilitam a inclusão social de pessoas com deficiência. 
Dessa forma, compreende-se por barreiras de acessibilidade as que se caracterizam como barreiras sociais, estruturais ou culturais e se estabelecem quando a sociedade valoriza negativamente as pessoas diferentes, que assumem um papel desfigurado quando não correspondem com o modelo humano mental e funcionalmente perfeito, originando as barreiras físicas (Grünewald et al., 2009).

Buscando respaldo na normatização, a NBR 9050, que entrou em vigor em 30 de maio de 2004, oferece critérios e parâmetros antropométricos para adaptação e construção de edificações, mobiliários, espaços e equipamentos urbanos às condições ideais de acessibilidade. Esta norma visa proporcionar à maior quantidade possível de pessoas, independentemente de idade, estatura ou limitação de mobilidade ou percepção, a utilização de maneira autônoma e segura do ambiente (ABNT, 2004).

Conforme Boiteux (2003 apud Reis, 2010), o Art. 20 do Código Mundial de Ética do Turismo menciona que as atividades turísticas devem respeitar a igualdade entre homens e mulheres, devem tender a promover os direitos humanos e especialmente os direitos particulares de grupos específicos tais como crianças, idosos, deficientes, minorias étnicas e os povos autóctones.

No Brasil, em 1999 a Embratur lançou um Manual de Recepção e Acessibilidade de pessoas portadoras de deficiência a empreendimentos e equipamentos turísticos para definir com detalhes de como deveriam ser o meios de hospedagem adaptados. Embora a utilização não seja obrigatória, o manual mostra as adaptações que devem ser feitas nos projetos hoteleiros. Pela quantidade de serviços que os hotéis oferecem como: alimentação, alojamentos, sala de reuniões, dependências de lazer e afins, são esses os equipamentos turísticos que mais exigem adaptações (Silva, 2004).

Entretanto, além da adaptação física, outro quesito igualmente importante que deve ser trabalhado para o pleno atendimento a esse público, refere-se a hospitalidade. Assim, tendo em vista que as PDMR estão já inseridas ou se inserindo no mercado de trabalho e são consumidores em potencial que se interessam e adquirem vários tipos de serviços, dentre esses, os serviços turísticos, começa-se a pensar nos fatores que agregam valor para que estas pessoas tenham a infra-estrutura necessária às suas necessidades. Fatores estes como adaptabilidade de todos os locais desde o perímetro urbano para que a locomoção seja facilitada independente da deficiência, até os meios de transporte em geral, os locais de hospedagem incluindo as dependências, dormitórios, banheiros e etc. (Reis, 2010).

Um outro aspecto relevante nesse processo refere-se a adequada formação para a prestação de serviços a este segmento. Entretanto, conforme abordam García-Caro, Waal \& Buhalis (2012), não há nenhum organismo de regulação e/ou aprovação da atividade, existindo grande variação nesse mercado. Os autores enfatizam que o turismo acessível precisa ser desenvolvido conceitualmente e incorporado nos programas de formação nos diferentes níveis da organização. Isto capacitará a indústria a promover a conscientização de funcionários e o alcance da qualidade total e um processo gradual mas contínuo. 
Corroborando, comparando-se a importância da adaptação dos ambientes e equipamentos com a capacitação na inclusão e geração de valor social (Borda \& Nascimento, 2011) pode-se perceber que é a capacitação das pessoas que recebem e atendem os PCDMR seja em agências de viagem, fornecendo informação adequada para a viagem; durante a viagem, nos meios de transporte; ou nos equipamentos turísticos, atrativos e meios de hospedagem do destino - que possibilita mais completamente a inclusão. São as pessoas integrantes do turismo receptivo - mais que a construção e adaptação de edificações, mobiliários, espaços, etc. - que vão fornecer a qualidade da experiência desse turista e possibilitar a sua percepção de inclusão social e seu encantamento ou não pelo destino (Borda, Duarte \& Serpa, 2013).

Numa perspectiva mercadológica, Fontes \& Monteiro (2009) argumentam que, contrário às abordagens clássicas do turismo, inspiradas em metodologias de marketing que segmentam os produtos turísticos em função das motivações de mercados, o turismo acessível parte de uma condição do turista, na medida em que busca ofertar soluções que permitam ultrapassar as limitações físicas, sensoriais, mentais - ou de outro tipo de incapacidade - que são condição limitativa do turista.

Em Brasília, de acordo com a Lei no. 3.298/DODF/2004, é obrigatória a disponibilização de cerca de $4 \%$ dos apartamentos e instalações sanitárias acessíveis aos portadores de deficiência física que utilizam cadeira de rodas, por hotéis e similares (Nurin/Prodide, 2004). Tal Lei dá um parâmetro aos estabelecimentos hoteleiros sobre o número mínimo de instalações que devem ser adaptadas para receber esse público com qualidade. Entretanto, faz-se necessário um estudo sobre potenciais aumentos de demanda decorrentes de eventos mundiais que ocorrerão no Brasil.

Atraídos pela beleza natural exuberante, diversidade de cenários, clima agradável e, principalmente, pelo acolhimento expresso na forma de ser do povo brasileiro, turistas nacionais e internacionais escolhem o Brasil para suas atividades de lazer: seja nos segmentos aventura, sol e mar, religioso, ecoturismo, entre outros, e até mesmo no turismo de negócios e/ou eventos. É nesse contexto que o estudo da inclusão social via acessibilidade às PDMR cresce em relevância.

\section{METODOLOGIA DO ESTUDO}

Tendo em vista o objetivo deste artigo, primeiramente foi realizada, como técnica de pesquisa, a bibliográfica, permeando um estudo exploratório dos assuntos relacionados ao tema proposto para fornecer o embasamento teórico necessário. Conforme Gil (1991), a principal vantagem da pesquisa bibliográfica reside no fato de permitir ao investigador a cobertura de uma gama de fenômenos muito mais ampla do que aquela que poderia pesquisar diretamente.

Além disso, o artigo revela-se exploratório principalmente na etapa da visita in loco aos hotéis localizados em Brasília, onde o objetivo foi verificar até que ponto os mesmos se encontravam devidamente adaptados para receber as PDMR e se em tais estabelecimentos havia alguma preocupação em relação a um eventual aumento de demanda. Dessa forma, entende-se 
que esse aspecto exploratório da pesquisa proporciona maior familiaridade com o problema em estudo, tendo como objetivo principal o aprimoramento de ideias (Gil, 1991).

Em relação ao tipo de amostragem, em função do caráter exploratório, este trabalho se enquadra como uma amostragem não probabilística, por acessibilidade, também chamada por conveniência. Nela o pesquisador seleciona os elementos a que tem acesso, é adequada e frequentemente utilizada para geração de ideias em pesquisas exploratórias. Tais tipos de amostras podem ser facilmente justificadas em um estágio exploratório da pesquisa, como uma base para geração de hipóteses e insights (Churchill \& Lacobucci, 1988; Oliveira, 2001). No caso específico deste estudo, ao todo, foram entrevistados 29 estabelecimentos.

Tendo em vista a natureza do presente trabalho, constata-se que o mesmo também apresenta uma fase descritiva, na medida em que aborda dados e problemas que merecem ser estudados e cujo registro não consta de documentos, trabalhando sobre fatos colhidos da própria realidade (Cervo \& Bervian, 2007). De acordo com Gil (2002), as pesquisas descritivas são, juntamente com as exploratórias, as que freqüentemente realizam os pesquisadores sociais preocupados com a atuação prática.

Como técnica de coleta de dados, além do levantamento obtido na etapa teórica, durante a pesquisa bibliográfica, elaborou-se um roteiro de entrevista composto por questões predominantemente fechadas, dividido nos seguintes blocos: caracterização do respondente; caracterização do estabelecimento; contexto atual; adaptação do estabelecimento; PDMR como segmento de mercado/clientes em potencial; PDMR e o mercado de trabalho turístico (hoteleiro); e Hóspedes pertencentes a terceira idade. A coleta de dados ocorreu no ano de 2012.

Por fim, o trabalho se enquadra como de cunho qualitativo. De acordo com Minayo (2004), a pesquisa qualitativa é capaz de incorporar aos dados a questão do significado, da intencionalidade como inerentes aos atos e às relações e estruturas sociais como construções humanas. Para a autora, a pesquisa qualitativa é importante por compreender os valores, a cultura e as representações dos grupos sobre o tema pesquisado, abrangendo as relações processadas entre os grupos sociais, tanto no âmbito das instituições, como no dos movimentos sociais.

\section{RESULTADOS DA PESQUISA DE CAMPO}

Como mencionado na metodologia, foram entrevistados, ao todo, 29 hotéis localizados em Brasília. $O$ instrumento de pesquisa utilizado foi dividido em blocos com o intuito de melhor analisar as variáveis de estudo. A seguir serão apresentados os principais resultados do estudo.

\subsection{Caracterização dos Respondentes e dos Estabelecimentos Pesquisados}

Participaram do estudo 29 respondentes de ambos os sexos (15 homens e 14 mulheres), funcionários de hotéis da cidade de Brasília, a maioria com idade na faixa de 30 a 40 anos, 
ocupantes das funções de recepcionista $(n=13)$ e gerência $(n=8)$, com até sete anos de experiência de trabalho no estabelecimento $(n=21)$.

Os estabelecimentos pesquisados contemplaram hotéis de micro e pequeno porte $(n=19)$ e de médio e grande porte $(n=10)$, com até 110 funcionários $(n=17)$ e 160 apartamentos $(n=16)$. A maioria dos estabelecimentos pesquisados (23 hotéis) possuíam instalações adaptadas.

Tabela 1 - Frequência de hotéis, considerando o número de apartamentos adaptados para receber PDMR.

\begin{tabular}{lc}
\hline Número de apartamentos adaptados & Frequência \\
\hline 4 a 6 & 12 \\
1 a 3 & 8 \\
Mais de 6 & 2 \\
Nenhum & 3 \\
5 (com 03 apartamentos em reforma) & 1 \\
Não respondeu & 3 \\
\hline Total $\quad n=$ frequência & 29 \\
\hline \multicolumn{2}{c}{}
\end{tabular}

Por fim, os estabelecimentos entrevistados se classificaram como 5 estrelas $(n=5) ; 4$ estrelas $(n=9) ; 3$ estrelas ( $n=8) ; 2$ estrelas ( $n=1)$ e 6 não informaram.

\subsection{Contexto Mundial}

O terceiro bloco de questões visava investigar como o entrevistado visualizava o Brasil e, mais especificamente, o seu empreendimento neste cenário mundial de instabilidade. A maioria (21 respondentes) considera que o contexto atual de instabilidade é positivo para o seu estabelecimento; 5 entendem que o contexto atual de instabilidade mundial pode influenciar negativamente o desempenho do seu estabelecimento; de forma similar, 1 estabelecimento afirma que "não se modifica, permanece constante"; outro afirma que é indiferente, pois "o residencial absorve diversos tipos de público que procuram locação"; e 1 considera que a atual crise mundial ainda não influenciou negativamente seu estabelecimento. Tais afirmações demonstram o sentimento positivo dos entrevistados sobre a economia brasileira frente a economia mundial, na qual o turismo parece não estar sendo abalado pelo contexto econômico externo.

Outra questão desse bloco indagava se, em virtude da proximidade de mega eventos, dentre os quais a Copa do Mundo em 2014, como o entrevistado considerava um eventual aumento da demanda de PDMR por seu estabelecimento. Ressalta-se que com a Copa Mundial de Futebol no Brasil (FIFA 2014), espera-se a geração de 2 milhões de empregos formais e informais e crescimento de $55 \%$ da entrada de reservas internacionais, aumentando-a de U\$ 3,94 bilhões para U\$ 5,56 bilhões de 2010 a 2014 (MTUR, 2010).

Dentre as respostas obtidas, 13 disseram que, apesar do seu estabelecimento não estar devidamente adaptado, está prevista uma reforma para melhor atender esse público; 12 
afirmaram não estarem preocupados, pois seu estabelecimento já possui instalações adaptadas para receber um eventual aumento de PDMR; 2 não possuíam opinião formada; 1 afirma que "se preocupa e que procura melhorar"; e 1 disse não se preocupar com um eventual aumento de demanda, pois acredita que isso não irá acontecer em virtude da Copa do Mundo. Analisando tais respostas, verifica-se que a maioria dos estabelecimentos pesquisados ( 26 hotéis) aparenta estar preocupada ou já preparada para um potencial aumento de demanda em função da Copa do Mundo.

\subsection{Adaptação dos Estabelecimentos}

As questões referentes a este bloco diziam respeito ao ponto focal deste estudo. Dos entrevistados, 26 afirmaram que seu estabelecimento está adaptado para receber hóspedes PDMR e 3 afirmaram que não são adaptados.

Quando questionados sobre o motivo de ter suas instalações adaptadas, dentre as alternativas assinaladas, 20 entrevistados afirmaram e que o estabelecimento foi adaptado para atender a legislação e 9 que o estabelecimento foi adaptado em função de entender as PDMR, um segmento em potencial. Constatou-se que a maioria dos estabelecimentos pesquisados adaptaram suas instalações apenas para atender a legislação (Lei no. 3.298/DODF/2004), o que reforça o indicativo que tal público parece não ser visualizado como um segmento de mercado. No que se refere ao tempo que esses estabelecimentos estão adaptados, 9 estão há mais de 6 anos; 9 estabelecimentos de 1 a 2 anos; 6 de 3 a 5 anos; e 2 há menos de 1 ano.

Focalizando a inclusão da Acessibilidade para Todos como um importante elemento

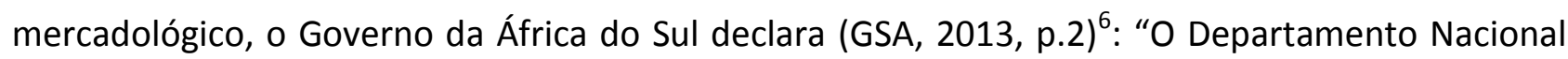
de Turismo identificou a Acessibilidade Universal no Turismo como uma importante iniciativa para ampliar a competitividade internacional da África do Sul”. Com essa declaração, percebe-se o destaque da acessibilidade como um diferencial competitivo pelo governo e pela cadeia produtiva da África do Sul - diferentemente da percepção do setor hoteleiro de Brasília - destacada na pesquisa.

Para aqueles que responderam que não possuíam suas instalações adaptadas perguntouse se estava previsto algum projeto para adaptar o estabelecimento: 2 respondentes responderam que não; e 1 afirmou que há um projeto, mas não soube dizer para quando o mesmo será realizado.

Quando questionadas sobre as características do seu estabelecimento quanto a acessibilidade no Hall do hotel e nos apartamentos, obteve-se os dados a seguir:

\footnotetext{
${ }^{6}$ The National Department of Tourism identified Universal Access in Tourism as an important initiative to enhance South Africa's competitiveness.
} 
Figura 1 - Frequência e especificação dos itens adaptados, por ambiente, nos hotéis pesquisados

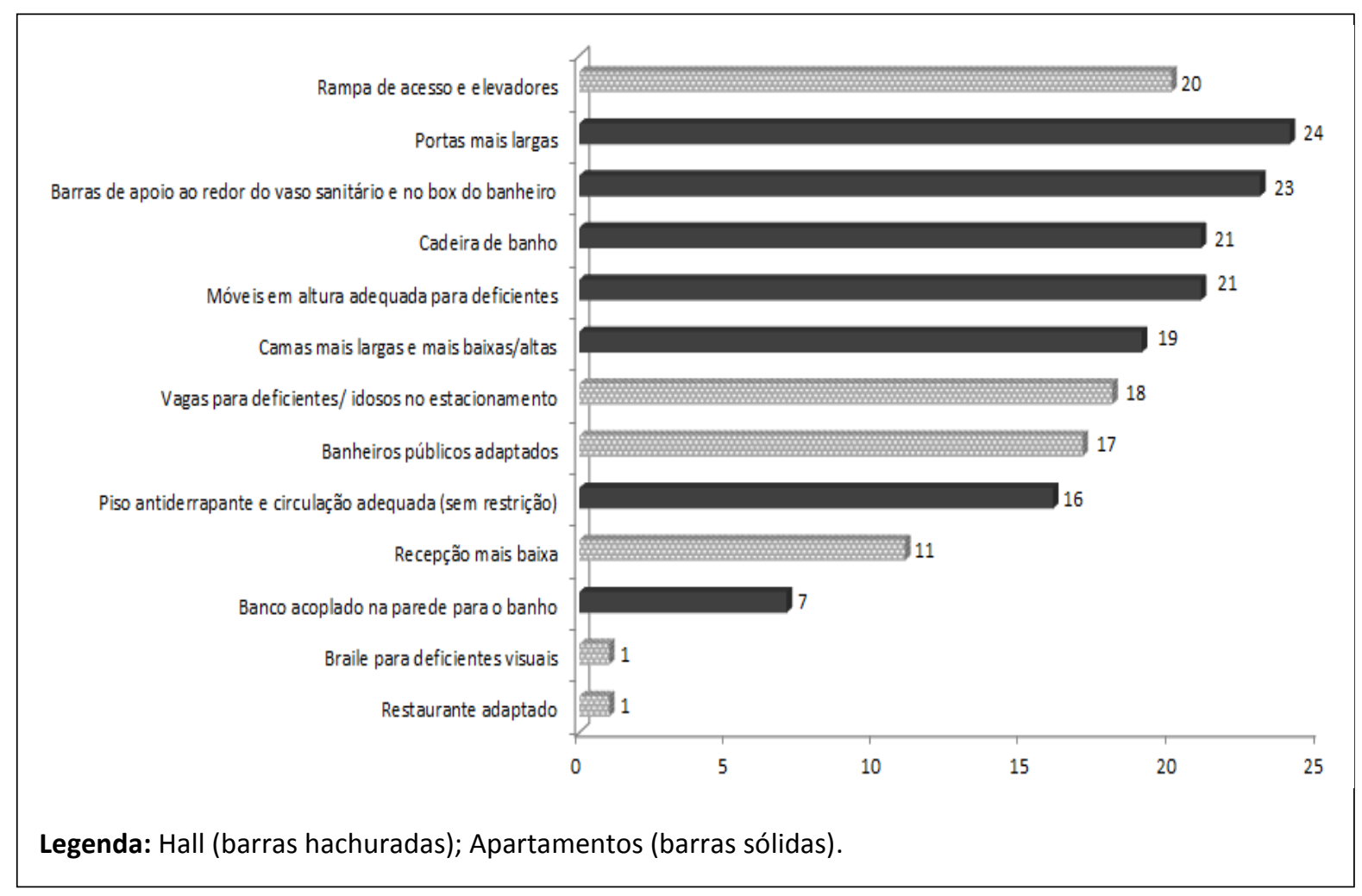

Tendo como base a figura 1 , constata-se que os itens mais assinalados foram: para os apartamentos as portas mais largas, seguida das barras de apoio ao redor do vaso sanitário e no box do banheiro, cadeira de banho e móveis em altura adequada para deficientes; já no Hall do hotel tem-se a rampa de acesso e elevadores, seguida da vaga para deficientes/idosos no estacionamento.

Sob o aspecto da necessidade de adaptação física dos estabelecimentos, Daruwalla e Darcy (2005) enfatizam a necessidade da indústria turística reconhecer que não oferecer serviços acessíveis pode ser considerado uma prática discriminatória e isso pode resultar em procedimentos legais com consequências graves, não só pelas perdas financeiras diretas, mas também pelas consequências ao nível da imagem negativa da empresa.

A pesquisa realizada apontou que 21 entrevistados afirmam que divulgam no seu endereço na web que suas instalações eram adaptadas; 7 estabelecimentos não divulgam e 1 não informou. Dos que não divulgam, foi questionado motivo de tal fato. Dentre as respostas, 3 consideram necessária a divulgação, embora isso ainda não seja feito; 2 não informaram; 1 considera que necessita de mais adaptação para ser divulgado; e 1 não sabe porque não é divulgado. Tendo em vista que a web atualmente se mostra como um grande divulgador de serviços, dentre esses os turísticos, e que o público alvo formado pelas PDMR necessita de informações fidedignas sobre o hotel no qual pretende se hospedar principalmente no que se 
refere a sua acessibilidade, vê-se imprescindível a divulgação das instalações adaptadas no endereço eletrônico do estabelecimento.

\subsection{PDMR como Segmento de Mercado/Clientes em Potencial}

Este bloco de questões visava investigar se o público formado pelas PDMR era visualizado como um segmento de mercado em potencial. A primeira questão perguntava se o hotel possuía algum desconto especial para os hóspedes PDMR. Dos pesquisados, 26 estabelecimentos mencionaram que não há descontos para esse público; 2 mencionaram que possuem descontos, ambos referentes a desconto na hospedagem; e 1 pesquisado não informou.

A próxima pergunta indagava como o entrevistado observava a procura de PDMR pelo seu estabelecimento (famílias com parentes PDMR ou hóspedes individuais). Os resultados são apresentados na Tabela 2.

Tabela 2 - Procura de PDMR pelo estabelecimento hoteleiro.

\begin{tabular}{lc}
\hline Nível de procura & Frequência \\
\hline Muito frequente (pelo menos 2 vezes a cada semestre ou ano) & 15 \\
Frequente (pelo menos 1 vez a cada semestre ou ano) & 6 \\
Pouco Frequente (1 vez a cada 2 ou 3 anos) & 5 \\
Raramente (1 vez a cada 4 anos ou mais) & 2 \\
Não soube informar & 1 \\
\hline
\end{tabular}

De acordo com a pesquisa, dos 29 pesquisados, 21 consideram que há uma procura frequente ou muito frequente desse público.

Sob o aspecto mercadológico, é válido lembrar a argumentação de Devile (2009) que considera um fator relevante desse segmento o seu alto nível de fidelização pois, quando satisfeitos, tendem a regressar àqueles destinos que lhes garantam acessibilidade.

A terceira e última questão desse bloco perguntava como o entrevistado considerava a relação entre as suas instalações adaptadas e a procura das PDMR pelo seu estabelecimento. Dezesseis entrevistados consideram que o fato de ter suas instalações adaptadas tem propiciado a procura dos seus serviços pelas PDMR e/ou suas famílias; 9 pesquisados relatam que o fato de ter suas adaptações adaptadas não tem influenciado ou aumentado a procura dos seus serviços pelas PDMR e/ou suas famílias; 2 afirmam não possuir instalações adaptadas; e 2 não responderam essa questão.

Com base nas respostas obtidas, pode-se considerar que a adaptação dos estabelecimentos entrevistados tem propiciado, em linhas gerais, a procura de PDMR e/ou por seus familiares. Vale lembrar que Brasília apresenta uma peculiaridade: a existência do Hospital Sarah Kubitschek, hospital que é referência nacional em reabilitação, com sede em Brasília. Tal fato pode influenciar na procura desse tipo de hóspede na capital federal. 


\subsection{PDMR e o Mercado de Trabalho Turístico (Hoteleiro)}

Este bloco de questões visava verificar o mercado de trabalho das PDMR no setor hoteleiro. A primeira questão perguntava se o hotel possui ou já possuiu empregados com alguma deficiência ou necessidade especial no seu quadro de funcionários. A grande maioria (19 entrevistados) mencionou que não e 10 responderam afirmativamente. Destes, perguntou-se quantos foram empregados, 3 responderam que empregaram em torno de 5 empregados; 1 que empregou 1 funcionário; e 6 não responderam.

Para aqueles que responderam que não empregam ou nunca empregaram PDMR no seu estabelecimento, perguntou-se o motivo de tal fato ocorrer. A maioria, 13 entrevistados, mencionou que nunca houve procura por parte das PDMR para trabalharem no seu estabelecimento; 2 relataram que não há vagas disponíveis para PDMR no seu quadro de funcionários; e 1 mencionou que seu estabelecimento não é adaptado para receber PDMR. Para estes entrevistados, perguntou-se ainda se havia a possibilidade de ofertar vagas para PDMR. Nove responderam que possivelmente, mas a longo prazo; 7 entrevistados mencionaram que sim; 2 não informaram; e 1 mencionou que não. Tais dados revelam que a maioria (16 entrevistados) pensam em ofertar vagas para PDMR no seu estabelecimento atualmente ou a longo prazo.

Para aqueles que responderam que empregam ou já empregaram PDMR no seu quadro de funcionários, questionou-se qual o motivo. Das respostas obtidas, 9 disseram que há uma política organizacional de inclusão social/inserção econômica dos PDMR; e 1 crê que a sustentabilidade social via inclusão social/inserção econômica é fundamental para um mundo melhor.

Com relação a sustentabilidade e emprego de PDMR, 9 entrevistados consideram que as PDMR empregadas pelo estabelecimentos se mostraram mais preocupadas/ou igualmente preocupadas com a sustentabilidade que os outros empregados; e 1 não possui PDMR no seu quadro de funcionários.

Em relação ao tipo de limitações dos funcionários PDMR que trabalham ou já trabalharam no seu estabelecimento. Sete possuem ou possuíam deficiência física; 6 deficiência auditiva; 4 deficiência mental; 1 não informou; e 1 mencionou que nunca empregou PDMR.

Ainda referente ao motivo para empregar PDMR; 6 consideram que há uma preocupação institucional com a responsabilidade social da organização; 1 acredita que a organização está inserida no Turismo Responsável e busca realizar ações de inclusão social/inserção econômica; e outro entrevistado acredita que alguns dos líderes se preocupam com a responsabilidade social e acreditam na inserção econômica de PDMR.

Quando questionados como o entrevistado considerava as PDMR e o mercado de trabalho no setor hoteleiro, a maioria ( 25 entrevistados) considerou que essas pessoas, apesar de suas limitações, podem estar inseridas como funcionárias no setor hoteleiro; 3 não responderam essa questão e 1 não tem opinião formada a respeito. 
Para aqueles que já empregaram PDMR no seu quadro de funcionários, 5 ocupavam o cargo de serviços gerais; 3 trabalhavam no restaurante; 2 no administrativo; 1 na portaria; 1 na manutenção predial/porteiro; e 1 como telefonista.

Em relação aos tipos de processo seletivo utilizados para selecionar esses funcionários, 8 utilizaram entrevista; 2 seleção por indicação do Sesi/Senac. Quando questionados se oferecem treinamento para esses funcionários, apenas 1 estabelecimento oferece algum tipo de capacitação para esses funcionários (no caso, treinamento no próprio local de trabalho); e 6 não oferecem.

Quanto à carga horária das PDMR, para 8 a carga horária de trabalho é igual aos demais funcionários; em um a carga horária é menor do que a carga horária dos demais funcionários. Para 7 entrevistados a renda mensal dos PDMR é igual aos demais funcionários e 2 não souberam informar.

\subsection{Hóspedes Pertencentes a Terceira Idade}

O último bloco de questões discutiu a terceira idade no setor hoteleiro. A primeira questão perguntava ao entrevistado como ele considerava a procura por hóspedes de terceira idade (a partir de 60 anos) no seu estabelecimento. Os resultados são apresentados na Tabela 3.

Tabela 3 - Procura de hóspedes de terceira idade pelo estabelecimento hoteleiro.

\begin{tabular}{lc}
\hline Nível de procura & Frequência \\
\hline Frequente (pelo menos 1 vez a cada semestre ou ano) & 21 \\
Raramente (1 vez a cada 4 anos ou mais) & 4 \\
Pouco Frequente (1 vez a cada 2 ou 3 anos) & 3 \\
Não soube informar & 1 \\
\hline
\end{tabular}

Dos estabelecimentos pesquisados, 21 não oferecem descontos especiais para hóspedes de terceira idade e 7 oferecem descontos na hospedagem para esse público.

Outra questão indagava se as instalações adaptadas ocasionavam maior procura por hóspedes pertencentes a terceira idade. As respostas demonstram um empate de opiniões, pois para 12 entrevistados o fato de ter suas instalações adaptadas tem propiciado a procura dos seus serviços por hóspedes de terceira idade e/ou suas famílias; entretanto, para 11 pesquisados o fato de ter suas instalações adaptadas não tem influenciado ou aumentado a procura dos seus serviços por hóspedes de terceira idade e/ou suas famílias; 4 hotéis entrevistados relataram não possuir instalações adaptadas e 1 hotel não possuía informação formada a respeito.

Quando questionados se o hotel oferecia algum tipo de serviço diferenciado para hóspedes de terceira idade, os itens mais assinalados foram banheiros adaptados (8 entrevistados); alimentação diferenciada (4 entrevistados); móveis em altura acessível (5 entrevistados); assistência médica (1 entrevistado); treinamento para atender esse público (1 entrevistado); direito a acompanhante (1 entrevistado). 
Tendo como base a pesquisa de campo realizada, a seguir são tecidas as conclusões do estudo feito no setor hoteleiro de Brasília.

\section{CONCLUSÃO}

Este trabalho teve como objetivo discutir a questão da acessibilidade e sustentabilidade no setor hoteleiro de Brasília. Com tal intuito, foram investigados 29 hotéis localizados na capital federal indagando como os mesmos abordavam a acessibilidade, entendida aqui num sentido mais amplo, trabalhando além de hóspedes com alguma limitação física, também o público formado pela terceira idade, haja vista que a adaptação necessária no estabelecimento pode atender a esses dois públicos. Além disso, tentou-se relacionar como os entrevistados visualizavam a questão da sustentabilidade por estes públicos. A pesquisa de campo revelou alguns dados que merecem ser destacados:

- a maioria dos estabelecimentos pesquisados (23 hotéis) possuíam instalações adaptadas;

- a maioria (21 respondentes) considera que o contexto atual de instabilidade é positivo para o seu estabelecimento. Tal fato, de certa forma, contradiz a análise da UNWTO (2011) que considera uma perspectiva mundial negativa em função do aumento de taxas sobre viagens e turismo em vários países, o que demandaria novos desafios para o setor;

- a maioria dos estabelecimentos pesquisados (26 hotéis) aparenta estar preocupada ou já preparada para um potencial aumento de demanda em função da Copa do Mundo;

- a maioria dos hotéis pesquisados (20 estabelecimentos) adaptou seu estabelecimento apenas para atender a legislação (Lei no. 3.298/DODF/2004), o que reforça o indicativo que tal público parece não ser visualizado como um segmento de mercado;

- 21 entrevistados afirmaram que divulgam no seu endereço na web que suas instalações são adaptadas e 7 não divulgam. Conforme visto do referencial teórico, as PDMR já estão inseridas ou estão se inserindo no mercado de trabalho e são, portanto, consumidores em potencial. Neste sentido, a divulgação que o estabelecimento é adaptado na web contribui com o pensamento dos autores apresentados no referencial teórico que defendem a ideia de uma sociedade inclusiva e de um turismo inclusivo (Silva \& Boia, 2003; Fontes \& Monteiro, 2009; García-Caro, Waal \& Buhalis, 2012; Pinto, 2009);

- dos 29 pesquisados, 21 consideram que há uma procura frequente ou muito frequente desse público e 16 entrevistados consideram que o fato de ter suas adaptações adaptadas tem propiciado a procura dos seus serviços pelas PDMR e/ou suas famílias. Isso demonstra que o estabelecimento, ao adaptar suas instalações, pode receber um aumento de demanda de PDMR, segmento esse que tem se mostrado expressivo, de acordo com o último senso do IBGE (2011); 
- quanto à empregabilidade, a grande maioria (19 entrevistados) mencionou que não possui ou nunca possuiu PDMR no seu quadro de funcionários, mas a maioria destes (16 entrevistados) pensam em ofertar vagas para PDMR no seu estabelecimento atualmente ou a longo prazo.

- para aqueles que responderam que empregam ou já empregaram PDMR no seu quadro de funcionários ou que possivelmente empregariam, 9 disseram que isso ocorreu devido a uma política organizacional de inclusão social/inserção econômica das PDMR;

- com relação a sustentabilidade e emprego de PDMR, 9 entrevistados consideram que as PDMR empregados pelo estabelecimentos se mostraram mais preocupados/ou igualmente preocupados com a sustentabilidade que/em relação aos outros empregados;

- a grande maioria (25 entrevistados) considera que as PDMR, apesar de suas limitações, podem estar inseridas como funcionárias no setor hoteleiro;

- no que se refere aos hóspedes pertencentes a terceira idade, a maioria (21 hotéis) considerou que há uma procura frequente (geralmente 1 vez a cada semestre ou a cada ano). Vale lembrar que, de acordo com o IBGE (2011), atualmente há 18 milhões de pessoas na terceira idade e um idoso em cada grupo de dez brasileiros;

- para 12 entrevistados o fato de ter suas instalações adaptadas tem propiciado a procura dos seus serviços por hóspedes de terceira idade e/ou suas famílias; entretanto, para 11 pesquisados o fato de ter suas instalações adaptadas não tem influenciado ou aumentado tal procura. Tais dados podem revelar que as instalações adaptadas podem ser indiferentes ao público formado pela terceira idade, entretanto seria necessário um estudo futuro para um maior aprofundamento dessa hipótese.

Deve-se ressaltar que o escopo deste estudo refere-se ao setor hoteleiro da capital federal, que apresenta peculiaridades, como por exemplo, ser a capital do país, o centro do poder político, além do fato de ser uma cidade nova e construída de forma planejada. Assim, entende-se que os resultados alcançados nesse estudo não podem ser entendidos como válidos para outras cidades/metrópoles, pois os contextos poderão ser absolutamente distintos. Entretanto, considera-se que seria válido um estudo comparativo dos resultados obtidos com outras cidades/metrópoles do país, inclusive com capitais de outros países, com o objetivo de comparar se a preocupação com a acessibilidade e a própria adaptação de tais estabelecimentos teriam ou não comportamento semelhante.

Por fim, conclui-se que os objetivos propostos inicialmente a este estudo foram plenamente atingidos. Entretanto, como a proposta inicial foi focada na capital federal, sugere-se, portanto, para estudos futuros, uma ampliação desse levantamento em outros setores relacionados ao turismo, como bares, restaurantes, transporte, aeroportos, entre outros. Assim, poder-se-á visualizar a questão da acessibilidade nos demais serviços relacionados ao turismo. 


\section{REFERÊNCIAS}

ABNT. NBR 9050:2004 (2004). Acessibilidade a edificações, mobiliário, espaços e equipamentos. Disponível em: <http://www.mpdft.gov.br/sicorde/NBR9050-31052004.pdf> Acedido em: 15 jan. 2013.

Boia, Y. (2000). O turismo e a pessoa portadora de necessidades especiais. 140f. Dissertação (Mestrado em Turismo e Hotelaria). Programa de Pós-Graduação em Turismo e Hotelaria, Universidade do Vale do Itajaí, Itajaí.

Borda, G. Z. (2009). A relação de confiança agregando valor: cases socioambientais de sucesso. In: FÉLIX, Bicalho, Joana D'Arc; Borda, Gilson Zehetmeyer (Orgs). Gestão da comunicação e responsabilidade socioambiental. São Paulo: Editora Atlas, p. 201-235.

Borda, G. Z. \& Duarte, D. C. \& Serpa, A. B. (2013). Tourism for All: accessibility and social inclusion in brazil the case of socorro (São Paulo State) Tourism Destination. In: international critical tourism studies conference $v$, Sarajevo, Bosnia \& Herzegovina, p. 31.

Borda, G. Z. \& Nascimento, E. P. (2011). Capital social organizacional: confiança e valor social. Polêm!ca, 10, pp. 103-114.

Cavaco, C. (2009). Turismo sénior perfis e práticas. Journal of Tourism Studies, Cogitur, 38.

Cervo, A. L. \& Bervian, P. A. \& Silva, R. (2007). Metodologia cientifica. 6. ed, São Paulo (SP): Pearson Prentice Hall.

Churchill, G. A. \& Lacobucci, D. (1988). Marketing research: metodological foundations, 2. Ed. Orlando: Dryden Press.

Daruwalla, P. \& Darcy, S. (2005). Personal and societal attitudes to disability. Annals of Tourism Research, 32(3), pp. 549-570.

Devile, E. C. P. G. L. (2002). Desafios e Oportunidades para o Desenvolvimento de Turismo para Pessoas Deficientes: reflexão sobre as suas necessidades da informação turística. In I CONGRESSO BRASILEIRO DE DOCÊNCIA E PESQUISA EM TURISMO. Campo Largo. Anais... Campo Largo, pp. 146-147.

. (2009). O desenvolvimento do turismo acessível: dos argumentos sociais aos argumentos de

mercado. Revista Turismo \& Desenvolvimento. n. 11, 39-46, 2009.

Duarte, D. C. (2005). Metodologia para desenvolvimento de portais de relacionamento de suporte a comunidades de prática: uma aplicação para a área de turismo e para pessoas com necessidades especiais, Tese de Doutorado, Departamento de Engenharia de Produção, Universidade Federal de Santa Catarina, Florianópolis.

Eurostat (2011). Population and structure ageing. http://epp.eurostat.ec.europa.eu/statistics_explained/index.php/Population_structure_a nd_ageing. Acedido em julho 2012.

Fialho, M. (2009). Rotas sem Barreiras. Revista Turismo \& Desenvolvimento. Journal of Tourism and Development, n. 11, pp. 109-112. 
Fontes, A. \& Monteiro, I. (2009). O Projecto "Lousã, Destino de Turismo Acessível": um estudo de caso da aplicação de uma abordagem sistêmica ao turismo acessível. Revista Turismo \& Desenvolvimento. Journal of Tourism and Development. n. 11, pp. 61-72.

García-Caro, S. N. \& Wall, A. \& Buhalis, D. (2012). Special Needs Customer Care Training for Tourism. In Aspects of tourism. Best Practice in Accessible Tourism: inclusion, disability, ageing population and tourism. Channel View Publications.

Gil, A. C. (1991). Métodos e técnicas de pesquisa social, São Paulo: Atlas.

. (2002). Como elaborar projetos de pesquisa. 4. ed. São Paulo: Atlas.

Goodwin, H. (2011). Taking responsibility for tourism. Leeds - United Kingdom: ICRT.

Grünewald, L. Et Al. (2009). Turismo accesible: sistema integral de información para implementar un turismo para todos. Disponível em: <http://www.turismoaccesible.com.ar/turismo/amf conceptos acc.htm> Acedido em: ago. 2009.

GSA - Government of South Africa (2002) Cape town declaration. Disponível em: <http://www.capetown.gov.za/en/tourism/Documents/Responsible\%20Tourism/Toruism_RT_2002_Cape_ Town_Declaration.pdf> Acedido em: nov. 2013.

GSA - Government of South Africa (2013) Responsible tourism. <http://www.tourism.gov.za/CurrentProjects/ResponsibleTourism/> Acesso em: nov. 2013.

Instituto Brasileiro de Geografia E Estatística (IBGE). (2011). Censo Demográfico 2010: resultados preliminares da Amostra. Disponível em: <http://www.ibge.gov.br/home/estatistica/populacao/censo2010/resultados_preliminares_amostra/defau It_resultados_preliminares_amostra.shtm> Acesso em: dez. 2011.

Minayo, M. C. S. (2004). O desafio do conhecimento: pesquisa qualitativa em saúde. (8a. ed). São Paulo: Hucitec; Rio de Janeiro: Abrasco.

Ministério do Turismo (MTUR). (2006). Turismo e acessibilidade: manual de orientações. Brasília: Ministério do Turismo.

- (2010). Brasil 2014: uma visão a partir do marketing e do turismo. Disponível em: <http://www.copa2014.turismo.gov.br/copa/copa_cabeca/detalhe/artigo_Josep-Chias_20100108.html>. Acedido em: ago. 2011.

Moscardo, G. (2006). Third-age tourism. In: tourism business frontiers: consumers, products and industry. Elsevier, Oxford, UK, pp. 30-39. ISBN 978-0-7506-6377-9. Disponível em: <http:3605_Gianna_2005.pdf http://eprints.jcu.edu.au/3605/> Acedido em: jul. 2012.

Nascimento, E. P. (1994). Hipóteses sobre a nova exclusão social: dos excluídos necessários aos excluídos desnecessários, Cad. CRH, Salvador, n.21, jul./dez., 29-47. 
Nurin/Prodide (2004). Núcleo regional de informação sobre deficiência - DF. Lei no. 3.298, 19 de janeiro de 2004. Disponível em: <http://www.mpdft.gov.br/sicorde/index.php/legislacao/5-acessibilidade-transportee-locomocao/52-adaptacao-de-logradouros-e-edificios-de-uso-publico/14-distrito-federal/distrito-federalleis/769-lei-n-3298-de-19-de-janeiro-de-2004 > Acedido em Jun. 2012.

Oliveira, S. L. (2001). Tratado da metodologia científica. São Paulo: Cengage Learning.

Papamichail, K. (2012). Accessible hotels: design essencials. In Aspects of tourism. Best Practice in Accessible Tourism: inclusion, disability, ageing population and tourism. Channel View Publications.

Pinto, P. C. (2012). Dilemas da diversidade: interrogar a deficiência, o gênero e o papel das políticas públicas em Portugal. Fundação Calouste Gulbenkian / Fundação para a Ciência e Tecnologia, Lisboa.

Reis, E. R. (2010). Deficiência física e atividade turística: um contraponto entre a legislação e a realidade. Belo Horizonte-MG.

Serpa, A. B. B. (2009). Acessibilidade para pessoas com deficiência e inclusão social no turismo: a experiência da cidade de socorro - SP. Dissertação de Mestrado. Centro de Excelência em Turismo - CET. Universidade de Brasília - UnB.

Silva, A. C. L. (2004). Acessibilidade de pessoas com deficiência aos hotéis de Brasília, Centro de Excelência em turismo - CET, Universidade de Brasília - UnB.

SILVA, Y. F. \& BOIA, Y. I. K. (2003). Turismo e responsabilidade social - uma reflexão sobre os direitos das pessoas com necessidades especiais. Turismo - Visão e Ação. v. 5, n. 1, jan./abr, 53-65.

UA/INATEL - Universidade de Aveiro/Fundação Inatel (2012). Potenciais benefícios do desenvolvimento de um programa europeu de Turismo Social para Seniores. Relatório II. Disponível em: <http://www.euseniortravellers.eu/export/sites/calypso/comun/documentos/pt/Relatorio_Estudo_Univ_A veiro_B2-FINAL.pdf> Acedido em jul. 2012.

Unwto (2011). General assembly nineteenth session gyeongju, republic of Korea, 8-14 October 2011 Report of the Secretary General. Disponível em: <https://s3-eu-west1.amazonaws.com/storageapi/sites/all/files/pdf/a19_05_report_sg_e.pdf>. Acesso em: 21 dez. 2011). 